\title{
Gestión y Administración Forestal Post-huracán Félix
}

\author{
Harold Wilson \\ (Comisión de Recursos Naturales-CRAAN) \\ Comité Consultivo Forestal (CCF-RAAN) \\ Bloque de Forestería Comunitaria BCF- RAAN)
}

En primer lugar sean todos bienvenidos. Quisiera compartir un poco lo que hemos hecho, hasta este momento, con el tema de Forestería Comunitaria como gestión después del paso del huracán Félix, y también cómo hemos venido coordinándonos con INAFOR y con algunas instituciones del sector forestal en el tema de administración. Y así también qué es lo que estamos proyectando para el futuro.

Siempre que se habla de forestería comunitaria surgen personas que se atribuyen ser las pioneras en esta modalidad. Creo que en la RAAN hay un equipo técnico que dio inicio a todas estas ideas. Y esto comenzó desde el 2005, en el periodo pasado del Consejo Regional, en donde estuvo presente en la Comisión Bayardo Thatum, que actualmente está dirigiendo el proyecto Corazón; también Jorge Canales, que ahora es subdirector del INAFOR (creo que por esta razón hay mucha colaboración de trabajo con él, ya que ha impulsado la forestería). Y así, también, muchos compañeros que se encuentran aquí presentes, como Alí, German, Suyapa, y otros actores que han contribuido mucho en ese tema y a los cuales también hay que agradecer su aporte.

\section{Comienzos de la forestería comunitaria}

Las actividades de forestería comenzaron en 2005, con un mandato que se dio a la Comisión de Recursos Naturales y el Medio Ambiente del Consejo Regional Autónomo (CRAAN), para presentar una estrategia forestal de la región. La comisión comenzó a trabajar y luego se formó, también por mandato del Consejo, el Comité Consultivo Forestal. A partir de esta fecha comenzó a trabajar este equipo técnico.

\section{Estrategia de forestería comunitaria en la RAAN}

El profesor Schwartz habló bastante sobre el tema, por lo que no quiero entrar en mucho detalle, pero me gustaría mencionar los objetivos generales que tenemos en la forestería comunitaria y que surgieron de las mismas comunidades.

\section{Objetivo general:}

- Fortalecer la participación de los pueblos indígenas y comunidades étnicas en la planificación, ejecución y gestión de actividades productivas sostenibles y certificadas de los bosques de la región.

Anteriormente, en la explotación del recurso forestal las comunidades únicamente participaban de forma indirecta. Venían los empresarios madereros con concesiones desde Managua, llegaban a la comunidad y compraban a los comunitarios sus arboles en 100 y 200 pesos cada uno y estos empresarios se llevaban todo el recurso forestal. Entonces, la idea con la forestería comunitaria es que las comunidades se apropien de sus recursos y puedan entender el valor que tiene este recurso tanto ambiental como económicamente.

\section{Objetivos específicos:}

- Contribuir a mejorar el nivel social y económico de la población comunitaria indígena de la RAAN, vinculada al manejo sostenible de sus bosques certificados, considerando todos los eslabones de la cadena productiva forestal.

- Promover la conservación de la biodiversidad y el uso sostenible de los recursos forestales de las comunidades indígenas, mediante el fortalecimiento de las capacidades locales, el cambio tecnológico y la competitividad en aras de lograr saltos importantes en materia de productividad y eficiencia del sector forestal en la RAAN. 
- Asegurar, a través del Comité Consultivo Forestal (CCF) y el bloque de forestería comunitaria en la RAAN, la armonización, alineación y apropiación de las intervenciones de los organismos de cooperación, en las actividades del sector forestal en la RAAN.

O sea, que con la forestería comunitaria queremos que las comunidades comiencen a cambiar sus estilos de vida. Porque teniendo tantos recursos en un bosque que representa tanta riqueza, no pueden seguir viviendo en la pobreza, sino que todos puedan aprovechar estos recursos y puedan mejorar su nivel de vida. Pero no sólo eso. La idea es que con la forestería comunitaria se pueda dar toda la cadena. Es decir, aprovechar la madera, transformarla y venderla. Pero también sembrar, reforestar, para permitir que las generaciones venideras tengan también este recurso a disposición. Porque en la RAAN existen todavía los bosques, debido a la presencia de las comunidades. Porque la sostenibilidad del bosque se debe al manejo que los indígenas han hecho de él. El Alcalde mencionó ayer esta relación entre las comunidades indígenas y el bosque. Porque el indígena aprovecha el recurso forestal para lo que necesita realmente. Por eso es que la explotación es sumamente sostenible. Se hace un manejo, se podría decir, de forma natural.
Con la creación del Comité Consultivo Forestal, la idea es que se pueda ir promoviendo esto e ir buscando alternativas para poder facilitar los recursos, las capacidades técnicas y el buen manejo del bosque por parte de las comunidades y de los bloques que hemos conformados en este momento.

\section{El proceso de formulación de la estrategia}

Se comenzó con la tarea de incidencia y promoción, primero con las autoridades regionales y luego con los líderes comunales y autoridades territoriales, consejeros municipales, regionales, instituciones rectoras, cooperación externa. Al inicio se escuchaba sobre forestería comunitaria, y por eso son famosos, los líderes de la comunidad de Layasiksa, específicamente Rufino Johnson que ahora anda viajando por todo el mundo hablando de forestería comunitaria. También Mateo, del bloque SIPBSAA, y compañeros de Las Crucetas que ahora también viajan por todo el mundo hablando de forestería. Estos compañeros surgieron de las primeras comunidades que practicaron la forestería comunitaria, los cuales hacían propaganda en asambleas, etcétera, $\mathrm{y}$ allí se vendió la idea. Aquí están presentes algunos de esos compañeros.

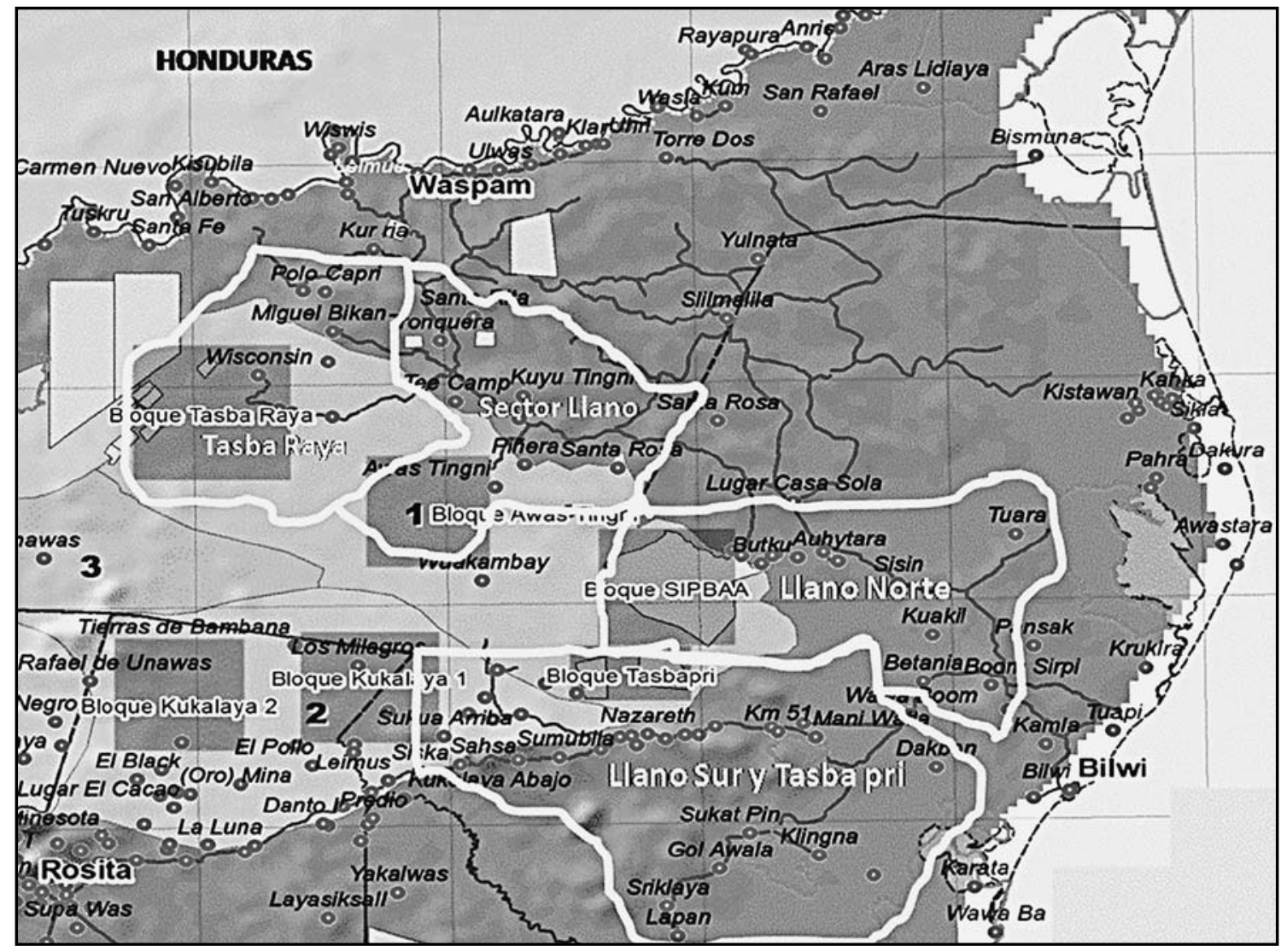

Diversos bloques y territorios en donde se encuentran ubicadas empresas comunitarias forestales. 
La secuencia de estas actividades fue la siguiente:

- Identificación de información primaria y secundaria.

- Entrevistas, reuniones de coordinación, armonización con actores interesados.

- Apoyo decidido del equipo de gobernanza forestal-CCF-RAAN

- Priorización (4) territorios indígenas con bosques en sus comunidades (PRINZAPOLKA, LAS MINAS, WASPAM y PUERTO CABEZAS).

- 52 COMUNIDADES INDIGENAS Y ETNICAS a CONSULTAR con 100 lideres participantes.

- APORTAN UN AREA POTENCIALDE 272,000 hectáreas predominante de bosque latifoliado abierto y cerrado.

- Compromiso de los interesados para promocionar el enfoque de forestería comunitaria (100\%).

Después del huracán Félix, la forestería comunitaria tuvo otro proceso. Tuvimos que acelerar este proceso, porque el bosque ya no estaba en pie sino que se encontraba tumbado por el fenómeno y teníamos que buscar de qué manera aprovechar esto al máximo, para que estos objetivos que habíamos planteado ahora se pudieran lograr.

\section{Lineamientos específicos EFC-RAAN}

- Incrementar áreas de bosques latifoliados y de pinares bajo manejo y certificación forestal con activa participación de los comunitarios dueños del recurso forestal.

- Fortalecer las capacidades administrativas, organizativas y de mercadeo de los pueblos indígenas y comunidades étnicas, incluyendo el componente de forestaría comunitaria en todos los programas y proyectos, empresas privadas, instituciones y universidades locales que estén vinculados al sector forestal.

- Contribuir a la resolución de conflictos a través de propuestas y mecanismos formales de diálogo que enfrenten los vacíos legales e institucionales relacionados con el reconocimiento de los intereses y derechos de las comunidades indígenas, con respecto a sus tierras, al uso de recursos forestales.
- Fomentar la seguridad alimentaria y la generación de ingresos mediante proyectos agroforestales, mediante la creación y consolidación de empresas forestales comunitarias.

- Sistematización y difusión de las experiencias de desarrollo forestal comunitario.

- Asistencia técnica y prestación de servicios en las áreas sociales, organizativas y culturales del desarrollo forestal participativo.

A Layasiksa y a otras comunidades les ha llevado muchos años desarrollar la forestería comunitaria, entre cinco y diez, y todavía están en proceso. Pero con el paso del huracán Félix, este proceso ha sido realmente muy intenso. Con el apoyo de las instituciones como el INAFOR hemos logrado que esto marche, pero estamos claro de que las 17 empresitas que hemos formado, unas van tener más avance que otras. En este sentido es necesario dar acompañamiento a estas empresas para que se desarrollen y puedan dar a sus comunidades estabilidad económica a través del aprovechamiento forestal y no solamente del recurso de madera, sino también del producto no maderable, medicinas. Los organismos no gubernamentales pueden apoyar con una inversión económica y obtener como pago servicios ambientales. Aunque en Nicaragua no hay mucha experiencia, como en otros países, las comunidades sin embargo deben ir apropiándose de aquí al 2010. Estas empresas comunitarias deben estar bien formadas y en buen funcionamiento, tal vez no en un $100 \%$, pero quizás un $70 \% \mathrm{y}$, por qué no, en un $90 \%$,

\section{Metas de las Empresas Forestales Comunitaria- RAAN}

Qué es lo que hemos alcanzado y lo que queremos alcanzar con este proceso de conformación de la forestería comunitaria.

1. Constituida la asociación de comunidades indígenas para el fomento y promoción de forestaría comunitaria, en la Región Autónoma Atlántico Norte (ACOIFCRAAN), como un bloque de forestaría a partir del segundo semestre del 2006.

2. Pueblos indígenas, comunidades étnicas, productores privados gozan de estabilidad social sobre el tema acceso a tierra (títulos de 
propiedad) con recursos forestales a partir del año 2007-2010.

3. Empresas forestales comunitarias formadas y funcionando con capital financiero inicial y acceso a mercado justo a partir del segundo semestre del 2006- 2010.

4. Sistemas agroforestales implementados en forma sostenible y generando ingresos en áreas comunitarias en la Región Autónoma Atlántico Norte a partir del año 2007.

\section{Actividades y tareas inmediatas de la EFC-RAAN}

1. Constitución del bloque de forestaría comunitaria en asamblea general con la participación de los delegados electos por territorios para tal acto. Esto ya se ha logrado.

2. Encuentro de validación de estrategia ante el pleno del Consejo Regional de la RAAN. Esto también se ha logrado

3. Organización de taller regional convocando a actores interesados para recepcionar apoyo para implementación de la estrategia de forestaría comunitaria acompañando a la asociación de comunidades indígenas con bosque en la RAAN (ACOIFCRAAN).

4. Facilitar el funcionamiento de la asociación (ACOIFCRAAN), para su gestión y desarrollo. Esto es un proyecto que queremos lograr. Creo que en este año podemos hacer funcionar esta corporación que es muy importante

5. Organización de territorios y comunidades con bosques, para formalizar convenios de trabajo con interesados. Esto se trata de convenios con empresas, comunidades y familias, que vayan promoviendo el manejo forestal

\section{Corporacion Forestal Comunitaria de la RAAN}

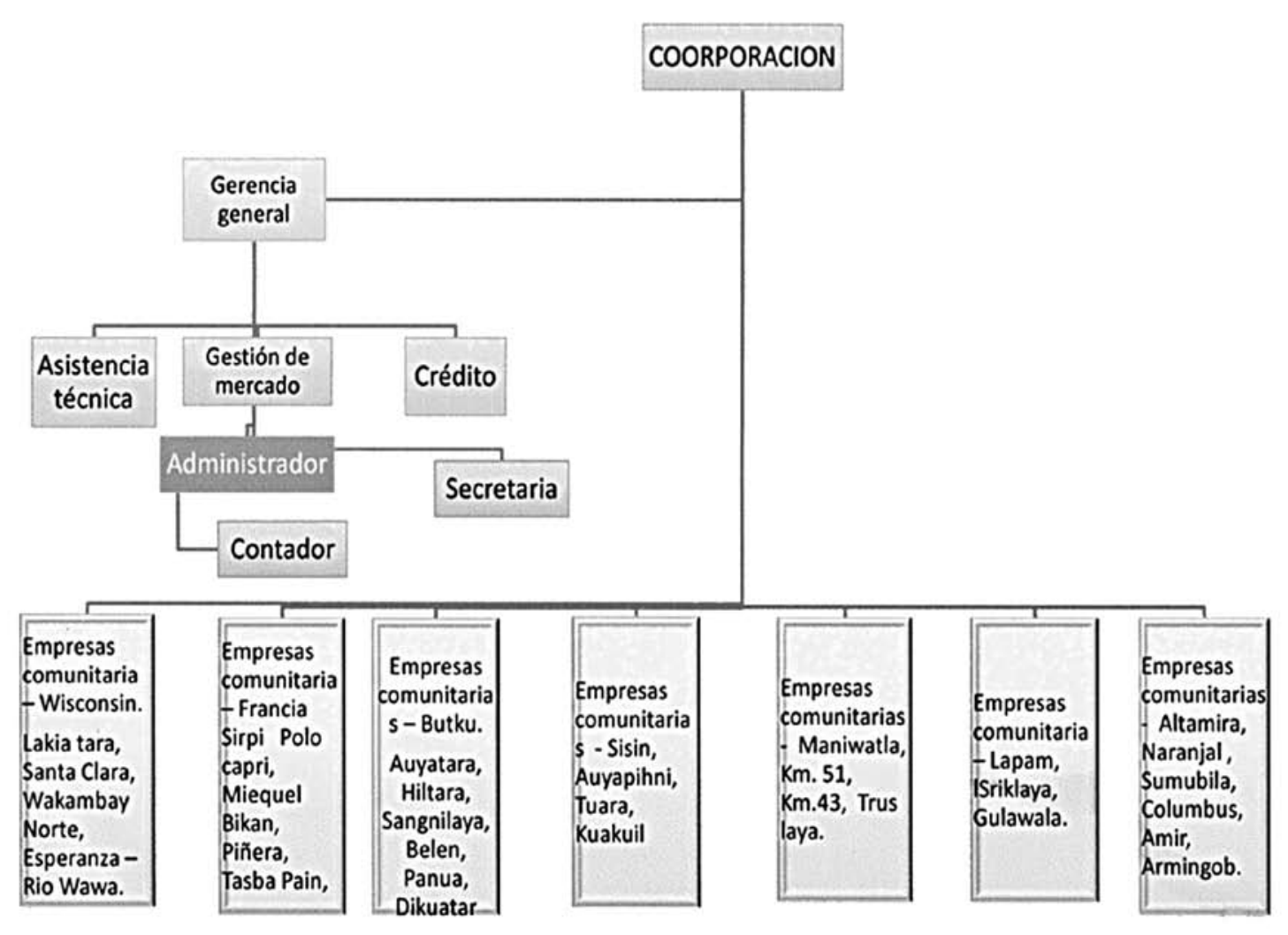


6. Formulación de propuesta de financiamiento para alcanzar las metas del componente ante FONADEFO y el Fondo de desarrollo regional-RAAN. En este sentido hay muchas oportunidades de financiamiento de organismos internacionales (Banco Mundial, GTZ, etcétera). Esperamos que esto se pueda consolidar y se establezcan líneas de créditos para estas comunidades con bosques.

7. Formulación y gestión de proyectos vinculados al proceso de inversión responsable sobre manejo forestal sostenible y certificado; incluye el tema de servicios ambientales.

\section{Normativas}

Esto es, hasta este momento, lo que tenemos en forestería comunitaria. ¿De dónde surgen todas esas cosas? Tal vez si menciono algunas normativas que hemos trabajado en el Consejo Regional después del paso del huracán podría explicar el origen de esto.

- Resolución del Consejo Regional No. 43-22-11-2007 Programa Ambiental de aprovechamiento y usufructo del recurso forestal afectado por el Huracán Félix.

- Resolución CRAAN No. 57-08-09-2007 Sobre la estrategia de Forestaría Comunitaria en la RAAN.

- Resolución CRAAN Procedimientos para la comercialización de la madera proveniente de los planes de aprovechamiento forestal de la madera caída por efecto del Huracán Félix. Trabajamos en esta resolución de un procedimiento de la recolección de madera caída, para hacer más fácil y accesible para las comunidades esta recolección

- Resolución CRAAN. Mecanismos de coordinación, regulación, monitoreo y control de actividades forestales a implementarse en la RAAN. En esto hemos trabajado muy a la mano con INAFOR, sobre todo en el tema de los permisos de recolección. En la Comisión de Recursos Naturales estamos trabajando para llevar un control de todos estos permisos y el movimiento de la madera. Estamos viendo también cómo controlar la tala ilegal. Queremos asegurarnos que todas las empresas, comunidades o personas aprovechen solo el recurso caído y no vayan a cortar madera en pie. Quiero decir sinceramente que controlar esto ha sido un esfuerzo muy difícil, puesto que INAFOR y las instituciones involucradas carecen de recursos suficientes para este tipo de monitoreo en la amplia área afectada $(1,200.000$ ha). Aunque hemos facilitado grandemente el aprovechamiento de la madera en el suelo, sin embargo existen muchos madereros que talan ilegalmente.

\section{PROXIMOS PASOS}

- Establecer mecanismos de coordinación e información sobre los avances en la implementación de la Estrategia de Forestaría Comunitaria. Existe un sinnúmero de instituciones y organismos que han venido aunando esfuerzo. Todos ellos están trabajando con esta estrategia. Sin embargo no tenemos control sobre lo que están haciendo, con qué financiamiento lo hacen, etcétera. Generalmente, cuando vienen buscan lo más fácil: trabajar con Laya Siksa, con el bloque SIPBSAA, con Cruceta. Sin embargo, todas estas comunidades ya están avanzadas en sus objetivos y metas, y estos organismos dejan de lado a las comunidades que tienen mayor necesidad de organización, de financiamiento, etc. El único que ha trabajado en esta línea es INAFOR. En ese sentido estamos convocando la próxima semana a un taller con estos ONGs, para visualizar sus intervenciones También hay organizaciones que quieren trabajar y buscan el aval de una comunidad, buscan financiamiento y luego desaparecen. En esta reunión vamos a mapear estas intervenciones y los evaluaremos en el marco de la estrategia que estamos implementando.

- Elaboración de la Estrategia de Regionalización Forestal. Esperamos en poco tiempo tener una estrategia definida.

Sé que ustedes tienen muchas preguntas, por eso he expuesto todo esto en forma general, para que podamos intercambiar ideas al respecto. 